\title{
Oppressed and Challenged but not Defeated: Families in Gaza Writes Back \\ https://doi.org/10.33806/ijaes2000.21.1.10
}

\author{
Elham T. Hussein \\ Al Ain University, UAE
}

\begin{abstract}
The longstanding occupation, military operations, and siege have left their imprint on all aspects of life in Gaza including the family as the core unit of society. This article analyses the impact of the Israeli practices on the structure of the Palestinian family as found in Gaza Writes Back: Short Stories from Young Writers in Gaza, Palestine. More specifically, the paper argues that although various forms of aggression and harsh humanitarian conditions have taken a heavy toll on the Palestinian society, they did not destroy the tightly knit traditional and patriarchal structure of the family nor did they render Palestinians completely submissive or silent. Furthermore, the author argues that the highly autobiographical stories in GWB give voice to Palestinians living under constant fear, humiliation and deprivation, a voice that is repeatedly dismissed or muted by the international community. As such, Gaza Writes Back is treated in this study as a work that belongs to resistance literature.
\end{abstract}

Keywords: family, Gaza Writes Back, Palestine, narrative, resistance literature

\section{Introduction}

The last few decades have witnessed a significant and steady growth in the volume and variety of Palestinian cultural production in English by Palestinian writers in the occupied territories and in the diaspora. In the field of historical studies, Edward Said, Rashid Khalidi, Walid Khalidi, Issa Khalaf, Salim Tamari, Nur Masalha, Nafez Nazzal and Beshara Doumani, among others, have produced texts that contest the Israeli version of the history of modern Palestine which is often taken for granted in the West. In addition, Edward Said, Ghada Karmi, Ramzi Baroud, Raja Shehadeh, Najla Said and Suad Amiry have all published memoirs which contextualize the Palestinian plight by blending the political and the personal. Others, such as Rosemary Sayigh, Mahmoud Zeidan, Fatma Kassem, Salman Abu Sitta and Dina Matar, have focused on oral history arguing that the voices of the people directly involved and impacted by the traumatic events of 1948 and after should indeed be considered a legitimate source for history. Alternatively, an expanding group, mostly from the younger generation, has chosen to express their ideas via the internet in blogs and opinion pieces. Still, Selma Dabbagh, Naomi Shihab Nye and Susan Abulhawa, to mention a few, turned to literature to creatively present the Palestinian take on the story. The anthology of short stories under discussion, Gaza Writes Back: Short Stories from Young Writers in Gaza, Palestine, $(G W B)$ which was published in 2014 , belongs to the last of these categories. 
In the introduction to $G W B$, Refaat Alareer, the editor, describes the collection as "the first of its kind" (2014a: 12) because it commemorates the fifth anniversary of Operation Cast Lead, the major military offensive Israel carried out against the people of Gaza between 27 December 2008 and 18 January 2009. But the collection is also the first, and, thus far, the only one of its kind because the stories are written in English by young Palestinian men and women, which has the benefit of eliminating translation-related problems (Moore-Gilbert 2016). According to a report by Amnesty International, during Operation Cast Lead around 1,400 Palestinians were killed, 5,000 were injured (some maimed for life), more than 3,000 homes were completely destroyed and 20,000 others were damaged, thus forcibly displacing thousands of people, many of whom were already displaced two or more times over (2009: 6 and 56). However, the scope of GWB expands well beyond the parameters of Operation Cast Lead to address themes related to the Palestinian master narrative of loss, displacement, endurance and resistance. This paper focuses on a less explicit, though by no means less important, theme in GWB: the impact of the Israeli occupation on the fabric of the Palestinian family. More specifically, the paper argues that although the various forms of extreme aggression and harsh humanitarian conditions have taken a heavy toll on the Palestinian family in Gaza, they did not break the tight-knit traditional and patriarchal structure of the family nor did they render Palestinians in Gaza completely submissive or silent.

To contextualize these stories and allow for a better understanding of the impact of the Israeli practices on the structure of the Palestinian family in Gaza, the broader historical and political background is necessary. According to Pappé (2017), the Israeli propaganda machine is relentless in presenting its policies and practices as out of context by turning "the pretext it found for every new wave of destruction into the main justification" for another spree of violence against Palestinians (91). A quick historical survey, however, shows that Gaza's current bleak reality, is the outcome of a systematic and comprehensive Israeli strategy towards Palestine in general and Gaza in particular compounded by the corruption of successive Palestinian governments and internal political divide.

\section{A brief history of Gaza since 1948}

Approximately 363 sq.km, Gaza Strip is a coastal territory along the Mediterranean Sea and borders Egypt on the southwest for eleven kilometres and Israel on the north and east for fifty one kilometres. At the outset of the 1948 Nakba (catastrophe), the port town of Gaza was not a strip but a town connected to the rest of Palestine. About 80,000 Palestinians lived in this area and depended on agriculture and small-scale industries for their living. The creation of Israel in 1948 had disastrous consequences on Gaza since the Strip was severed and isolated from the rest of the Palestinian territory. In addition, an estimated number of 200,000 Palestinian refugees who were forced to leave their homes elsewhere flooded Gaza and strained the economy. As a result of the massive influx of refugees, Gaza's population tripled overnight. Having lost their means of livelihood, the refugees became largely dependent upon UNRWA rations. 
The Strip was under Egyptian military rule from 1949 to 1956 and again from 1957 to 1967. In 1956, the Israeli military occupied the Strip and withdrew after six months only to re-occupy it during the Six-Day War in 1967. Overpopulation, poverty and scarcity of resources did not prevent Israel from building a chain of settlement blocs in the Strip, and by 2005, there were approximately 8,000-9,000 settlers in Gaza constituting half percent of the total 1.5 million inhabitants but in control of 20 percent of the territory and 40 percent of its recourses. Settlements came to dominate the geography of the Strip exclusively securing access to much of the best lands, water, shore areas, and roads (LeVine 2009).

The first Palestinian Intifada (uprising) broke in December 1987 in Gaza and then spread to the rest of the Palestinian territories. In 1993, Yasser Arafat, the chairman of Palestine Liberation Organization, embarked on secret negotiations with Israel and eventually signed the Oslo Accords which contributed to bringing the first Intifada to an end. According to the Accords, the control of Gaza was to be transferred to the Palestinian Authority (PA), but the presence of the settlements justified the transfer of only 60 percent of the area. Israel began the process of evacuating the settlers from Gaza and relocating them on the borders in August 2005. It was claimed that this move would allow Palestinians to build a viable and peaceful state. In reality, however, the Strip was transformed from a pocketed prison to the world's largest prison causing Gaza to suffer "unparalleled economic catastrophe" (Petersen 2007).

The elections for the Palestinian Legislative Council were held in January 2006, and Hamas won a decisive majority. Using Hamas as a pretext, Israel declared Gaza a "hostile entity" and escalated its oppressive practices to unprecedented measures. These practices included closing all crossings which resulted in further restriction on the movement of people and goods; stepping up violence through repeated military operations; withholding funds Israel was legally obliged to transmit to the PA, and even cutting off the flow of water to the Strip (Chomsky 2007). Thus, Israel created an unprecedented form of control in Gaza through a blend of new and familiar technologies of violence and spatial control, disengagement, closure and periodic bombing (Winter 2015). Between 2008 and 2014, Israel waged three wars, euphemistically labelled 'operations' by Israel: Operation Cast Lead (2008), Operation Pillar of Defence (2012) and Operation Protective Edge (2014). These assaults resulted in the death of at least 3,825 people, the injury of 18,056 people and the displacement of more than 760,000 people while simultaneously tightening the grip on Gaza.

The devastating blockade of Gaza entered its $13^{\text {th }}$ year last June, and the city, which is one of the most densely populated areas in the world, continues to suffer the consequences of the Israeli collective punitive system for its "refusal to be a docile ghetto" (Khalidi 2014). A recent UNRWA report shows that 80 percent of the population is dependent on international assistance, over 54 percent is unemployed and 90 percent does not have access to clean water (2019). To call for the Palestinian right of return and demand the ending of the Israeli blockade, tens of thousands of Palestinians in Gaza participated in the "Great March of Return" near the fence separating Gaza from Israel in the period between 30 March 2018 
and 22 March 2019. Though these weekly demonstrations were largely peaceful, 195 Palestinians, including 41 children, were killed and 28,939 were injured by Israeli forces (United Nations Office 2019).

\section{Gaza Writes Back and the importance of narration}

The above conditions of besiegement, military incursions, repeated displacements, and death have deeply impacted not only the way the young male and female contributors to $G W B$ write, but more importantly the way they perceive themselves and relate to the world around them. In a study on the relationship between constructions of personal identity and the Palestinian master narrative and collective identity among Palestinian youth, Hammack concludes that the engagement of the contemporary Palestinian youth with the tragic master narrative of loss supported by the social structure of the ongoing intractable conflict and the Israeli military occupation is most notably manifested in the reproduction of tragic stories of loss and dispossession (2010: 507).

Combining various narrative styles, the highly autobiographical stories in $G W B$ give voice to Palestinians living under constant fear, humiliation and deprivation, a voice that is repeatedly dismissed and muted by the international community. Edward Said aptly argues that narratives which question the Israeli representation of the Palestinian-Israeli conflict are frequently blocked, denied or simply dismissed and forgotten even when reality on the ground strongly supports them (1984). Following its establishment in 1948, Israel's political authority has allowed it to sustain the textual power of its narratives (Masri and Hamdi 2018) while simultaneously blocking counter narratives from forming and emerging (Said 1994). In other words, "it is mainly because of Israel's qualitative existence on the world political map that its narrative on Palestine has been sustained, circulated, and communicated as a dominant discourse not only in Israel but also in the pro-Israeli West" (Masri and Hamdi 2018: 8). To counterbalance the dominative and coercive Israeli version of the Palestinian history and struggle, Said has repeatedly called on Palestinians to produce their own forms of knowledge (see for example, 1984: 3738). He has specifically focused on narration as an important form of cultural production which Palestinians, like all colonized people, need to employ in order to assert their identity and resist erasure (1994, xii). As such, contesting the colonial narrative becomes an act of defiance and resistance. Within this theoretical framework, GWB could be said to belong to "resistance literature," a term coined by Ghassan Kanafani and presented by Barbara Harlow as an "arena of struggle" (1987: 2; emphasis in original). In addition, $G W B$ insists on self-representation because narrations by insiders who have lived the traumatic events are naturally more legitimate, authentic and reflective of reality than those put forth by outsiders.

The stories in $G W B$, provide graphic illustrations of what Said describes as "the disturbingly familiar ideas about flogging or death or extended punishment being required when 'they' misbehaved or became rebellious, because 'they' mainly understood force or violence best" (1994: xi). Having experienced Operation Cast Lead firsthand, Refaat Alareer, editor and one of the contributors to 
$G W B$, concludes that Israeli forces targeted life and hope in Gaza to ensure that following the offensive people will have nothing to cling to and that they are silenced, forever (2014b). Therefore, in GWB, storytelling becomes an essential ingredient of Palestinian life, defiance, and sumud--steadfastness (Alareer 2014b).

Indeed, the book's title, cover and the themes of numerous stories readily capture this spirit of defiance and resistance. For instance, the inclusion of "Palestine" in the title Gaza Writes Back: Short Stories from Young Writers in Gaza, Palestine, resists Israel's systematic and persistent attempts to erase the name of Palestine from the world map and from people's memory. In addition, while the Israeli occupation is relentless in its attempts to separate Gaza from the rest of Palestine, both the title and the book cover insist on the unity of the historical Palestine and on Gaza's inseparability from the Palestinian societal fabric. Hence, the stories are written by contributors living in Gaza which is part of Palestine, and the book cover does not feature an image of or from Gaza as would be expected, but an image of the Dome of the Rock in Jerusalem, besieged and distant. Finally, the theme of resistance is as central to the stories as other themes typically found in Palestinian literature: existential insecurity, rootedness in the land, and the moral and ideological justness of the Palestinian cause

The rest of this paper will focus on the impact of the Israeli occupation on the fabric of the Palestinian social structure. More precisely, it will demonstrate that though the Israeli occupation had undeniably affected the roles assumed by members of Gazan families, it had not succeeded in destroying the family structure, weakening the strong familial bonds or killing the spirit of resistance.

\section{The Palestinian traditional family}

Until the end of the British Mandate in 1947, the Palestinian society was predominantly agrarian (Shemesh 2004:91 and Mir 2013: 119), patriarchal and conservative (Abudi 2011: 9-16) with the family (both immediate and extended) constituting the basic source of social stability around which the individual's socioeconomic activities revolve. Unlike the Western view of the individual as a self-contained and autonomous entity, "interdependence, sentimentality, commitment, and claims of self-denial" (Barakat 1993a:100) are central to the Arab and Palestinian family. In fact, the strong interdependence among family members blurs the boundary between the individual and the family so that the individual and his or her family become one entity, and the success or failure of one member affects the entire family (Barakat 1993b:100-105).

Political upheavals, wars and displacement have disrupted the family life of all Palestinians (Abudi 2011; Monterescu 2006), though the Palestinian society continues to be patriarchal and hierarchical (Abudi 2011). Highlighting the impact of political instability and wars on all Arabs, Hisham Sharabi maintains that "[ $[\mathrm{t}] \mathrm{he}$ frustrations and humiliations, the rage and despair engendered by this state of affairs have led, since 1948, but particularly since 1967 , to the paralyzing trauma engulfing the Arab world" (1988: vii). Losses were particularly heavy for Palestinians since Palestine, as a geo-political entity, was erased from the map, and the Palestinian socio-economic structure was shattered: Palestinians lost their land and, thus, their 
source of livelihood and unifying centre; and the social framework of the extended family (hamula) as the primary source of social stability disintegrated as entire villages broke up and dispersed (Shemesh 2004:90).

At the turn of the $20^{\text {th }}$ century, the Palestinian society was homogenous and stable with a predominantly peasant population working on the land and following a lifestyle inherited from their forefathers. For the Palestinian peasants, land was the primary, and quite often, the only source of livelihood and the prime symbol of the father's prominence over family members. Land also functioned as a unifying unit bringing members of the extended family together. Therefore, when Palestinians lost their land, they lost their primary source of livelihood, security and unity. Moreover, the loss of land carried psychological significance as it is often equated with the loss of honour and social power.

In addition to land confiscation, Israel has also used house demolition, deportation and incarceration to purposefully weaken, burden and control the Palestinian family. According to Abdo:

The targeting of the Palestinian home, house and family has been and continues to be used as Israel's systematic policy for controlling Palestinians. House demolitions are only one example of this policy. Founded on its perception of the importance (read, demographic danger) of the Palestinian family and home (2008:35).

Colonial practices transformed the largely homogeneous Palestinian social structure into fragmented and scattered communities of refugees who are dependent on the UNRWA for shelter, food, medical care and education. Consequently, the family structure significantly changed causing the sharp line between the duties of males and females on the one hand, and parents and children, on the other, to become less distinct. For example, both the loss of land and property, the basic material constituent of the patriarchal system, as well as the rarity of job opportunities, seriously impacted the father's ability to provide for and to protect his family (Barakat 1993a:100-101). As a result, the father's traditional role as the guardian "of the normative and ethical system" (Monterescu 2006: 126) was largely compromised.

\section{Family in Gaza Writes Back}

Numerous stories in the collection shed light on the way families in Gaza struggle to survive under conditions of structural violence and economic oppression (Hammad and Tribe 2020: 1791). In most of the stories, the father is not presented as the breadwinner, the protector and the one in control. Instead, the "death of the father," either physically or metaphorically, is a recurrent theme. Still, the father continues to be the primary source of inspiration and courage for his children. The mother, on the other hand, is shown to be solely concerned with the physical wellbeing of her family members, as their psychological wellbeing is beyond her control. Despite her dedication, however, she rarely succeeds in protecting them. Perhaps the most resilient family members in GWB are the young sons and 
daughters who step up to fill the void left by the death of the father figure and the helplessness of the mother.

In eleven of the twenty-three stories included in the collection, the father is either already dead as a direct or indirect result of occupation when the story begins, or he dies before it concludes. In the stories where the father does not die, he is significantly weakened and his ability to support and control his family is seriously compromised. However, the father continues to be a symbol of steadfastness and to inspire his children to remain hopeful and defiant.

In "Please Shoot to Kill," the father, Abu Laila, is numbed by the intimidation of bullets and is "frozen by his inability to ensure the safety of his wife and children" (96). When armed Israeli soldiers break into the family's house, they intentionally humiliate the father in the presence of his family members. A soldier "grabbed Abu Laila's hair from the back, sinking his untrimmed nails in his scalp, and forced him on his knees" (96). Helpless and fearful for his family more than for himself, Abu Laila lowers his eyes and takes the hits and kicks soundlessly (97). Before leaving the house, the soldiers insult the family, spit on the floor, shoot at the father and seriously injure him.

The story of Abu Laila gives an example of a particularly painful experience shared by many Palestinians: the humiliation of Palestinian fathers at the hands of Israeli soldiers before the eyes of their wives and children. A survey of 3,000 Palestinian children during the first Intifada, for example, revealed that $45 \%$ of these children had seen their fathers being beaten by Israelis (Brittain 2001). Exposure to violence and humiliation, especially when witnessed by the wife and children, threatens the father's masculinity and foregrounds the limits of his power. As Peteet aptly suggests, the Israeli occupation "seriously diminished those realms of practice that allow men to engage in, display and affirm masculinity by means of autonomous actions. Frequent witness to their fathers' beatings by soldiers or settlers, children [became] acutely aware of their fathers' inability to protect themselves and their children" (Peteet 2000:107). Abu Laila sinks into deep depression not only because of months of physical pain and deteriorating health but also as a result of a deep sense of helplessness and powerlessness (101). Eventually, Abu Laila dies and the family is left with the tormenting memories of the incident, the war, and the death of the father. However, these painful memories function as a source of inspiration for Laila, the protagonist, and motivate her to join the medical school to become a doctor and help her people.

Like Laila, Mariam, the young narrator and protagonist of "L for Life," witnesses the shooting of her father while telling her a bedtime story. The memory of the father and his death does not pale with the passage of time. As a matter of fact, only at the time of the story and eleven years after his death, does Mariam begin to understand the enormity of the loss (31). Mariam becomes haunted with the father's unfinished tale especially as he had repeatedly pointed out physical similarities between her and Thaer, the young male protagonist of the father's story (the word thaer in Arabic means a revolutionist). However, anticipating an imminent fate, the father desires for the connection between Thaer and Miriam to go beyond physical similarity: "He is a boy who lost all his family to death but 
never lost faith in life. I want you to be as strong" (32-33). For Miriam, Thaer is not merely a fictitious protagonist in a story about freedom fighting, but an extension of the father's presence in her life (33). Miriam's father dies, but his legacy to fight the occupier continues through his inspirational story and through Mariam who takes it upon her shoulder to continue Thaer's legacy of defiance.

In other stories where the father is not dead or does not die, his authority and ability to support and fend for his family (and for himself) are significantly weakened, but he never loses hope. In "The Story of the Land," the narrator's father is devastated because the Israeli bulldozed his trees. He griefs not only because the uprooting of trees will affect the family's food supply, but more importantly because "land and agriculture have come to symbolize Palestinian resilience and perseverance in the face of ongoing land loss due to prolonged occupation" (United Nations Conference 2015: i). For the three years that followed the incident, the father sinks into severe depression and becomes silent and numb to all that was happening around him (59). However, his soul is rekindled when he receives agricultural facilitating supplies which help him re-plant his land. Thus, the father in this story sets an example of Palestinian sumud, or "determination to exist through being steadfast and rooted in the land" (Nguyen-Gillham, Giacaman, Naser and Boyce 2008: 292). Palestinian sumud is further emphasized through the father's concluding words: "By uprooting plants and cutting trees, Israel tries to break the bond and impose its own rules of despair on Palestinians. By replanting their trees over and over again, Palestinians are rejecting Israel's rules. 'My Land, my rules,' says Dad" (64).

"House" is the only story in the collection where the father is still in control of his family and is engaged in explicit, albeit limited, acts of defiance against the occupiers. Despite the objections of his wife and son, Abu Salem takes his son on an educational if perilous journey to the house which the family was forced to evacuate three years earlier. Both men understand that by paying a visit to their house they are defying the occupier and exposing themselves to a great danger, but the obstinate Abu Salem is not to be deterred. When they reach the house, Abu Salem leaves the explosives he had carried with him without connecting them since his goal was not to destroy the confiscated house but to create a sense of fear in the Israelis and to make them "feel that we are breathing down their neck" (133).

As the above discussion illustrates, stories in GWB show that the ability of the father to protect and provide for his family (two extremely important roles for the father in the patriarchal family) are seriously compromised. However, the father continues to be the most important source of inspiration for his children even after his disappearance and/or death. In comparison, the mother figure in GWB seems to have minimal impact on her sons and daughters. She is repeatedly portrayed as submissive, weak and totally occupied with her domestic duties, a role that meets the predicament of women in the patriarchal structure.

This image of Palestinian women contradicts the way they are represented in an emerging body of literature, which argues that Palestinian women are subjected to double oppression at the hand of colonization and patriarchy and that they are 
actively engaged in defying both (See Haj 1992: 761-778; Holt 2003: 223-238; Azzouni 2010). However, Kuttab rightly points out that prioritizing women's issues and rights is rather unrealistic when "all the Palestinian people, men and women alike, were being denied their basic human and national rights"(2009:106). In $G W B$, there is almost no reference to patriarchal oppression of women or to women's active participation in the struggle against the patriarchal structure or the occupying power. Instead, the Israeli occupation which inflicted immense losses on all women, especially mothers, has left them barely capable of fulfilling their traditional roles as nurturers and homemakers.

In "L for Life," "Will I Ever Get Out," and "One War Day," the reader briefly meets mothers who lose their husbands and struggle to preserve the lives of their children and to keep their homes intact. They are often overwhelmed by grief and the loss of loved ones and can do little to alleviate the suffering inflicted on their family members. The death of the father in "L for Life," for example, has dramatically changed the mother who became disinterested in and indifferent to the world around her. She now suffers in "bitter loneliness," and with every day that goes by she becomes frailer (34). The mother in "Will I Ever Get Out" loses her husband first and then her oldest son. With every death she too becomes weaker and can only raise her hands and pray to God (72). Similarly, the widowed mother in "One War Day" finds herself absolutely helpless before the Israeli war machine which kills and injures many members of her family.

While the mother in the above stories plays a peripheral role, in "Bundles," "Once Upon a Dawn" and "Scars," she occupies the central scene. These three stories present powerful narratives of mothers for whom the anguish of many losses, but especially that of children, is still raw several years after they occurred. The death of a child is generally considered the most intense and debilitating form of loss a person could experience for, in the natural order of life, children are expected to outlive their parents. Bereaved parents usually lose their hopes and dreams for the future, and even their identity. This makes them prone to experiencing prolonged grief and "intense feelings of guilt, impotence and worthlessness" (Crowe 2006).

Haunted by memories of their lost children and feeling guilty for outliving them, the mothers in GWB cannot live normal lives nor can they get a sense of closure. In "Bundles," Salma reminiscences over the time when she set off to visit her son, Naji, for the first time three years after he was imprisoned. The story about Salma and Naji is particularly troublesome not because of its uniqueness but because of its prevalence in the Palestinian society. Statistics show that the per capita incarceration rate of Palestinians is the highest in the world (Hajjar 2005: 202). In addition, Palestinian parents know that when their children are arrested, they are physically and psychologically abused by the Israeli soldiers, and that they are typically detained for a long time before trial (Chishti 2014: 40-44). Burdened with bundles containing goods for her son, Salma tolerates the long and humiliating inspections and questionings, but she is devastated when told that she has to be subjected to a cavity search. Salma is left with two terrible choices: agree to this violation of body and dignity or refuse it and, therefore, lose the chance to see her 
son. A comment by Abu Salem, the protagonist of "House" in $G W B$, about choices under occupation eloquently summarizes Salma's dilemma. According to Abu Salem:

Having choices under occupation has long become a thing worse, much worse, than being deprived of choices altogether. They oblige you to choose between two good options or two bad ones. In both cases, we are to suffer and sacrifice. We then have to live with the nightmares of choosing one over the other (131).

Salma chooses not to accept the humiliating cavity search, and, therefore, gives up on seeing her son. Three years after this incident and six years since she last saw him, Salma still lives the nightmarish consequences of her choice. She is consumed by feelings of sadness, guilt and longing for Naji who died in the prison without ever seeing his mother again.

"Once Upon a Dawn" too revolves around a widowed mother who is incapable of overcoming feelings of 'melancholic recollections' (153) and 'torturing regret' (154) over the death of her baby who was killed while asleep when an Israeli missile struck their home. Since then, it has become a nightly ritual for her to write letters to the dead son trying to explain to him, and to herself, what had happened. "The future seemed to decay that night," she writes. "Hope seemed to be thinning. Only you gave me hope; only your future gave mine a purpose" (158). Similarly, the female protagonist of "Scars" is depressed and hopeless after losing many dear members of her family. Racked with guilt for being the only survivor of her family, she wishes that death would rid her from the tormenting memory of the dismembered bodies which keep emerging in her dreams (170).

Stories in $G W B$ provide powerful examples of how the daily suffering of mothers in Gaza shattered their lives and made them forget their rights, needs and even selves and only think of how to protect their families. The stories also show that when their beloved ones, especially children, are harmed or killed, these women lose interest in life and become depressed and indifferent to life. Understandably, during times of extraordinary upheavals and wars, social liberation and political activism become less immediate and relevant for women since far more primal and existential issues keep them occupied (Roy 2006: 40-54).

Children and young people in $G W B$ also suffer immensely under repressive Israeli practices. Surprisingly, however, they seem to be more resilient than their parents. News and statistics about children and youth in Gaza are alarming. A report by Save the Children, for example, states that the fact that children in Gaza have experienced three wars and a total blockade, "has led to chronic poverty and restricted their freedom of movement outside Gaza [...]the ongoing instability and feelings of entrapment have left [many of them] with a deep sense of insecurity, fear and hopelessness, and have had a profound impact on their mental health and well-being" (2019:4). The first sentence in another report warns that a "generation of children are growing up in Gaza scarred by severe trauma and addicted to violence" (Brittain 2001). These excerpts summarize the way Palestinian children and youth are typically portrayed: either as objects of 
depression and post-traumatic stress disorder or as pathological adolescents who commit senseless acts of violence (Nguyen-Gillham et al. 2008: 292).

While the stories in GWB do not deny the troubling impact of occupation on the psychological and physical state of Gazan children, on the one hand, nor the possibility of their engagement in acts of violence, on the other, they also provide an important context which demonstrates that trauma and aggression are natural outcomes of the violence and injustice they are constantly subjected to. In addition, the stories show that the children and youth of Gaza are still resilient and altruistic despite the tattered social conditions caused mainly by the occupation.

The dwindling authority of the father figure which resulted from his inability to protect and provide for his family, his physical disability or death, profoundly impacted the role the young sons and daughters in $G W B$ assumed. For example, the death of the father forced Said in "Will I Ever Get Out?" Hamza in "One War Day" and Naji in "Bundles" to prematurely become the heads, and the only breadwinners of their families, to give up on their personal dreams and accept dangerous jobs in order to provide for their families. The three stories show how young Gazans repeatedly find themselves torn between difficult choices, and how they often act altruistically sacrificing not only their dreams, but also their lives to help their families. Said's final thoughts before he dies demonstrate the oneness of his and his family's pain and fate: "A hymn. I can hear a hymn now. My mother's prayer. My sister's empty stomach. The smell of burned flesh. And the flavour of sea water" (74).

In all the above stories, it is the oldest son who assumes responsibility for the family upon the father's death. In "Please Shoot to Kill," however, there are no male children and, therefore, Laila, the young female protagonist, steps up to fill the void. She contemplates quitting her university because the memory of her father's suffering prior to his death keeps replaying in her head "like a never-ending wheel" (95). However, she forces herself to stay strong all along and not to allow any sign of weakness to take hold of her. Therefore, when "an intense tear" trickles down her face, "her hand moved up swiftly to wipe it off, as though it were a sin to cry" (95). At the end of the story, though extremely angry with the Israeli occupation which caused her family to suffer, Laila is defiant and determined to pursue her and her father's dream to become a doctor.

Being caught in the vicious cycle of violence and aggression is another important aspect of the lives of Gazan children and youth which "Spared," "Omar $\mathrm{X}$ " and "Canary" address. These stories show how "Palestinian children appear to be at the greatest risk of exposure to various forms of violence" (Boxer et al. 2013: 173), on the one hand, and why they are "at the greatest risk for exhibiting various forms of aggressive behaviour" (Boxer et al. 2013: 163-177), on the other. The three young protagonists are psychologically scarred as a result of witnessing the killing and maiming of loved ones at the hands of the Israeli occupation, and, together, their stories show that in the context of occupation, injustice and war, it is normal and understandable that children show high levels of aggressive behaviour especially against the aggressor. 
In "Omar X," an autobiographical story based on the story of the author's fourteen-year-old brother who was killed at the hands of Israeli soldiers, Omar is said to have always suffered from curfews, night searches, humiliation and the killing of close friends by the Israeli soldiers. As he grows up, "he realizes that the soldiers, who used to scare him as a five-year-old boy on his way to kindergarten, still invade every little aspect of his life" (110). Therefore, he grabs his gun and sets off with his friend to fight the occupier. The fact that Palestinian youth in GWB are shown to resort to violence only in response to the violence they have been subjected to, speaks back to claims that Palestinian children and youth are innately violent simply because they belong to a "pathological culture that celebrates brutal, wanton death" (Garfinkel 2011). In effect, GWB gives a glimpse into the oppressive limbo these youngsters live in, a limbo marked by deprivation, night raids, siege, house demolitions, displacement, imprisonment and violent deaths. The stories also show that the susceptibility of Gazan children and youth to trauma and their tendency towards aggressive behaviour are natural outcomes of the horrendous conditions they live in.

\section{Conclusion}

GWB provides a platform for the oppressed Palestinians in Gaza to present their narrative of what happened during Operation Cast Lead, and, by extension, what has been happening in Palestine since it has become an occupied land. The stories show how the longstanding conflict, siege and military operations in Gaza impact the lives of individuals, families and, thus, the entire society. As fathers, who are traditionally the heads of families and the bread winners, are often targeted by the occupying apparatus, women and children are forced to fill out the void caused by the actual or metaphorical death of the father. The little support Gazans receive from the international community not only taught them ways to survive and deal with the harsh conditions of occupation, but also to rely less on the outside community and to be extra supportive of each other (Rabaia, Saleh and Giacaman 2014: 174). GWB also shows that the young writers of the stories are well-aware of the devastating impact of occupation and siege on all members of the community, yet they chose to fight back by holding on to hope as well as through narrating their stories in English in an attempt to make the world listen and understand.

Elham T. Hussein

English Language and Translation

Al Ain University, United Arab Emirates

ORCID Number: 0000-0002-3421-2453

Email: elhamrambadwi@yahoo.com 


\section{References}

Abdo, Nahla. (2008). 'Palestinian munadelat: Between western representation and lived reality'. In Ronit Lentin (ed.), Thinking Palestine, 25-45. London \& New York: Zed Books.

Abudi, Dalya. (2011). Mothers and Daughters in Arab Women's Literature: The Family Frontier. Boston: Brill Academic Publishers.

Alareer, Refaat. (2014a). Gaza Writes Back: Short Stories from Young Writers in Gaza, Palestine. Introduction. Virginia: Just World Books.

Alareer, Refaat. (2014b). 'Gaza Writes Back: Narrating Palestine'. Biography, 37(2): 524-537.

Amnesty international report. (2009). Israel/Gaza Operation Cast Lead: 22 days of death and destruction.

https://www.amnesty.org/download/Documents/48000/mde150152009en.p df (Retrieved on 10 May, 2019).

Azzouni, Suheir. (2010). 'Palestine - Palestinian authority and Israeli-occupied territories'. In Sanja Kelly and Julia Breslin (eds.), Women's Rights in the Middle East and North Africa, 359-397. New York, NY: Freedom House.

Barakat, Halim. (1993a). The Arab Family and the Challenge of Change. Berkeley: University of California Press.

Barakat, Halim. (1993b). The Arab World: Society, Culture and State. Berkeley: University of California Press.

Boxer et al. (2013). 'Exposure to violence across the social ecosystem and the development of aggression: A test of ecological theory in the IsraeliPalestinian conflict'. Child Development, 84 (3): 163-177.

Brittain, Victoria. (2001). Trouble in store for war-scarred sons of Gaza. The Guardian. https://www.theguardian.com/world/2001/apr/13/israel2 (Retrieved on 2 September, 2019).

Chishti, Naheed. (2014). 'Palestine in current scenario: A critical study'. Journal of Global \& Scientific Issues, 2 (3): 40-44.

Chomsky, Noam. (2007). Guillotining Gaza. Information clearing house. Information Clearing House. https://chomsky.info/20070730/ (Retrieved on 7 September, 2019).

Crowe, Liz. (2006). When a child dies - A guide to working with bereaved parents after the death of a child from illness. Centre for Palliative Care Research and Education, Queensland Health. 
https://www.health.qld.gov.au/data/assets/pdf file/0024/143097/when chil d dies.pdf (Retrieved on 7 September, 2019).

Garfinkel, Renee. (2011). The Gaza syndrome. Psychology Today. https://www.psychologytoday.com/blog/time-out/201103/the-gazasyndrome-0 (Retrieved on 27 October, 2019).

Haj, Samira. (1992). 'Palestinian women and patriarchal relations'. Signs, 17(4): 761-778.

Hajjar, Lisa. (2005). Courting Conflict: The Israeli Military Court System in the West Bank and Gaza. Berkeley: University of California Press.

Hammack, Phillip. (2010). 'The cultural psychology of Palestinian youth: A narrative approach'. Culture \& Psychology, 16(4): 507-537.

Hammad, Jeyda and Rachel Tribe. (2020). 'Social suffering and the psychological impact of structural violence and economic oppression in an ongoing conflict setting: The Gaza Strip'. Journal of Community Psychology, 48(6): 1791-1810.

Harlow, Barbara. (1987). Resistance literature. New York: Methuen

Holt, Maria. (2003). 'Palestinian women, violence and the peace process'. Development in Practice, 3: 223-238.

Khalidi, Rashid. (2014). Collective punishment in Gaza. The New Yorker. http://www.newyorker.com/news/news-desk/collective-punishment-gaza (Retrieved on 5 November, 2018).

Kuttab, Eileen. (2009). 'The Palestinian women's movement: From resistance and liberation to accommodation and globalization'. Graduate Institute Publications: 101-116.

LeVine, Mark. (2009). Tracing Gaza's chaos to 1948. Al Jazeera.http://www.aljazeera.com/focus/arabunity/2008/02/20085251857 37842919.html (Retrieved on 3 June, 2018).

Masri, Ahlam and Tahrir Hamdi. (2018). 'Where is Palestine in Caryl Phillips's The Nature of Blood?' International Journal of Arabic-English Studies, 18(1): 7-22.

Mir, Salam. (2013). 'Palestinian literature: Occupation and exile'. Arab Studies Quarterly, 35(2): 110-129.

Monterescu, Daniel. (2006). 'Stranger masculinities: Gender and politics in a Palestinian-Israeli third space'. In Lahoucine Ouzgane (ed.), Islamic Masculinities, 123-142. London: Zed Press.

Moore-Gilbert, Bart. (2016). 'Palestine, postcolonialism and pessoptimism: Palestine and postcolonial studies'. Interventions, 6:1-34. 
Nguyen-Gillham, Viet, Rita Giacaman, Ghada Naser and Will Boyce. (2008). 'Normalizing the abnormal: Palestinian youth and the contradictions of resilience in protracted conflict'. Health \& Social Care in the community, 16 (3): 292.

Pappé, Ilan. (2017). 'Historical Perspective of the 2014 Gaza Massacre.' In T. J. Coles (ed.), Voices for Peace: War, Resistance and America's Quest for Full-Spectrum Dominance, Sussex: Clairview Books.

Peteet, Julie. (2000) 'Male gender and rituals of resistance in the Palestinian intifada: A cultural politics of violence'. In Mai Ghoussoub and Emma Sinclair-Webb (eds.), Imagined Masculinities: Male Identity and Culture in the Modern Middle East, 103-126. London: Saqi Books.

Petersen, Kris. (2007). The Gaza strip: Disengagement two years on. The Electronic Intifada. https://electronicintifada.net/content/gaza-stripdisengagement-two-years/7228 (Retrieved on 10 July, 2019).

Rabaia, Yoke, Mahasin Saleh and Rita Giacaman. (2014). 'Sick or sad? Supporting Palestinian children living in conditions of chronic political violence'. Children \& Society, 28 (3): 172-181.

Roy, Sara. (2006). Failing Peace: Gaza and the Palestinian-Israeli Conflict. London: Pluto Press.

Save the Children. (2019). 'A decade of disorders: The harsh and unchanging reality for children living in the Gaza Strip'. https://resourcecentre.savethechildren.net/node/16724/pdf/a_decade_of_d istress_online_-_v3.1.pdf

Said, Edward. (1984). 'Permission to narrate'. Journal of Palestine Studies, 13 (3): $27-48$.

Said, Edward. (1994). Culture and Imperialism. London: Vintage.

Sharabi, Hisham. (1988). Neopatriarchy: A Theory of Distorted Change in Arab Society. New York: Oxford University Press.

Shemesh, Moshe. (2004). 'The Palestinian society in the wake of the 1948 war: From social fragmentation to consolidation'. Israel Studies, 9(1):86-100.

United Nations Office for Coordination of Humanitarian Affairs. "Approaching the first anniversary of the "Great March of Return" protests in Gaza'. https://www.ochaopt.org/content/approaching-firstanniversary-great-march-return-protests-gaza

United Nations Conference on Trade and Development. (2015). The besieged Palestinian agricultural sector. https://unctad.org/news/besiegedpalestinian-agricultural-sector (Retrieved on 4 January, 2020). 
UNRWA. (2019). Occupied Palestinian territory emergency appeal. https://www.unrwa.org/sites/default/files/content/resources/2019 opt ea final.pdf (Retrieved on 9 January, 2020).

Winter, Yves. (2015). 'The siege of Gaza: Spatial violence, humanitarian strategies, and the biopolitics of punishment'. Constellations: An International Journal of Critical and Democratic Theory, 23 (2): 308319. 